\title{
Does School Environment Exacerbate Achievement Gaps? Evidence from Ghanaian Public Senior High Schools
}

\author{
Richard Kwabena Akrofi Baafi \\ PhD Scholar, Faculty of Education and Psychology, Eötvös Loránd University (ELTE), Hungary
}

\begin{abstract}
Learning achievement gaps continue to be experienced in many learning institutions despite various policy and institutional measures to reduce learning inequalities among various categories of learners especially in developing nations. This study attempted to establish whether or not school environment exacerbated learning achievement gaps among students in senior secondary schools in Ghana. The study utilized mixed methodology in addressing the relevant research questions in the study. The study established that pertinent elements of within class and within school learning environment like proportion of poor students in the school or class, proportion of students from low SES, and proportional of most at risk students in classrooms, and level of student truancy was associated to incremental achievement gaps among students in senior secondary schools in Ghana. The study recommends for an affirmative action in the management of such cohorts of students in senior secondary schools so as improve schools learning environment and reduce achievement gaps in such schools.
\end{abstract}

Keywords: Achievement gaps, senior secondary schools, school environment.

DOI: $10.7176 / \mathrm{JEP} / 11-7-09$

Publication date:March $31^{\text {st }} 2020$

\subsection{Introduction}

Student achievement has dominated education process research in the recent past. This is after the famous Coleman report (Coleman et al., 1966) which alluded that the effects of student background factors on learning outcomes supersede those of school resources. However, after the Coleman report and the famous education production function studies, recent scholarly evidence seems to shift attention towards the role of school environment on influencing variance in student learning outcomes witnessed all over the world. School achievement is directly affected by effective learning and teaching and other complex social, physical, and psychological events within the school set-up (Machry, Knorst, Tomazoni, \& Ardenghi, 2018). Nonetheless, the exact organisational factors and the related psychological mechanisms related to the achievement gap are still under study.

To identify the means that positively impact the school learning outcomes has remained a great subject of academic inquiry and a major objective of both international bodies and government. Due to this interest, a lot of work that is centred on the effects of the school environment on the achievement gap has emerged. The school environment is the social norms of a school in relation to the relationship of students and teachers, norms and values, learning and teaching habits, and the shared practices and approaches. Among other factors, there is clear empirical evidence that confirms that the school environment is very powerful in affecting the academic achievement of students. A study carried by Lage, Platt, and Treglia (2000) established that schools with small class sizes allow teachers an opportunity of making movement within the class which ensures active participation among all learners and reduction of student truancy during the learning process.

A study carried out by Everett Jones, Brener, and McManus (2003). Established that school environment ranges from the physical environment within the schools and the physical environment which directly influences the process of teaching and learning. The study further established that the availability of the facilities is not a necessary and sufficient indicator of quality teaching and learning unless those facilities meet the required utility threshold and are actually utilized during the teaching and learning process. Moreover, the exact psychological issues underpinning the environment-achievement link is a subject under study (Stiggins, 2015). In order to fill these gaps, the research examines whether school environment exacerbates achievement gaps in schools.

There exist very few studies on this topic and even fewer using a robust, standardized, national measure to determine achievement. The research further examines the identity approach. The approach is based on work that has previously applied the social identity approach to variety of school achievement and is linked at improving achievement in school. Various academic journals have indicated that students from economically disadvantaged background are less capable compared to students from wealthy families. Further, studies have suggested that children from marginalized and poor families have a challenge in controlling their behaviors and emotions which negatively impact academic achievement in higher levels. Further, Amponsah, Milledzi, Ampofo, and Gyambrah (2018) found out that, the academic outcome from children from a poor background is severely affected by poor adult expectations. Moreover, researchers have concluded that parents' income is correlated to the development of the children. The outcomes were impacted by the fact that wealthy parents typically invest six times as much on the development of their children compared to the less affluent families.

Besides, researchers suggested that wealthy families provided more cognitively supporting environment for 
their children who are based on various opportunities for informal development, exposure to various books and meaningful conversations. Further, Rasamiravaka, Rasoanandrasana, Zafindraibe, Alson, and Rasamindrakotroka (2013), reported that children from well-off backgrounds typically had both parents having a university education. In contrast, children from poor families were often living with a single parent having little or no education. When affirmative actions are put in place to improve the achievement gaps, it will directly translate to better performance and keep the vulnerable groups in school. Such actions include equal access to competent teachers, eradication of culture mismatch, exposure to informal learning, and parent engagement. When such core values are upheld, more girls will finish school, students from poor families will have an environment to sustain them in school, school drop-out will reduce and the achievement gap will be reduced based on gender and economic background of students.

\subsection{Literature Review}

There are various challenging viewpoints that explain why achievement gaps exist in society. A myriad of the causes and the possible solutions related to the achievement gap have been discussed in the literature. The issues are often related to variances in socio-economic status, school inputs, and variances in teacher qualities. Little has been identified as regards whether the classroom and school environment have a significant influence on student achievement.

\subsection{Classroom learning environment}

Classroom learning environment entails the physical learning environment which consists of the availability of necessary physical learning facilities, the social and psychological atmosphere created as a result of the relationship among learners as well as that among students and teachers. The level of engagement in learning as well as teacherstudent engagement characterises emotional classroom environment which an endogenous measure of the school environment (Chapman \& Ludlow, 2010). Classroom sizes can also depict the classroom learning environment. Big class sizes are characterised with minimal teacher-student engagement and high levels of student truancy(Chapman \& Ludlow, 2010).

However, after an in-depth review of the research, So and Brush (2008) concluded that putting more emphasis learning and teaching aptitudes together with effective delivery of content knowledge resulted in higher dividends towards a learning environment and had more significant benefits compared to reducing class sizes. As researchers noted, the efforts made to improve the school environment, which translated to better student achievement addressed changes in teachers' and students' beliefs, attitudes and values as well as their level of motivation. Also, the over-reliance on standardised classroom tests has been criticised by researchers who argued that a significant proportion of the variance standardised results was directly affected by the socio-economic status of the students having the test, and continuous poor performance in standardised tests could negatively influence school environment (Kumi-Yeboah, 2016).

Other studies allude that there exist gender disparities in student achievement as a result of variance in the school environment (Cheryan, Meltzoff, \& Kim, 2011). Other studies argue that poor school environment negatively influences most at-risk student populations. Therefore, determining what aspect of the school environment makes some schools have a higher achievement for most at risk-students, whereas others do not have similar performance is an extremely complex issue. Other studies argue that students level of discipline and behaviours influences school environment (Lage et al., 2000).

Various scholars have also linked the behaviours of the students determined by teachers to be inappropriate or disruptive as a significant factor causing the achievement gaps. Student indiscipline is an indicator of a poor school learning environment. Schools or classrooms with high levels of student indiscipline has been found to increase learning achievement gaps (Ethier, Harper, \& Dittus, 2018). It should be noted that students who are poor academically often experienced frustrations that caused disruptive behaviour in the class set-up. Moreover, researchers have found out that gender, ethnic composition among teachers and students impacted on the school environment. The above differences greatly influenced the probability of students being viewed by the tutors as not being attentive, showing disruptive behaviour, or having incomplete homework assignment (Anderman, 2010). The perception by teachers that students looked unmotivated or looked in a manner likely to suggest lack of effort has been linked to achievement gaps.

\subsection{School Environment}

The school environment is a key factor in the achievement gap in most senior schools in Ghana. For instance, lack of access to advanced instructional facilities in most senior high schools that have a higher number of students from low-income families (i.e., low-income boys, and girls) are all under-referred in the traditional teacher/parent referral system for talented and gifted programmes (Asante, 2010). Moreover, when controlling the performance of students after assessment, differential access to more developed courses, rigid tracking, and other academic opportunities in senior high schools, students from poor and marginalised background are not likely to be admitted 
in honour-level courses or other advanced programmes even though they may have achieved good grades and controlled their aptitude (Potter, 2017).

\subsection{School Environment and Gender Disparity in Participation, Completion and Transition}

The school environment has been alluded to greatly influence gender disparity in performance besides completion and transition rates from one level of learning to another. For instance, in a society or school environment where gender equality is achieved, students perform better, and all this is attributed to a conducive school environment where violence, rape and other social ills are overlooked. Schools which are perceived as not safe will have more girls dropping out than boys since girls are more susceptible to dropping out than boys (Morton, Atkin, Corder, Suhrcke, \& Van Sluijs, 2016). Besides, societies with gender equality have always had a higher literacy level because the completion and transition of students to institutions of higher learning is almost $100 \%$, and as such, gender disparity plays a vital role in achievement gap depending on the society.

On the other hand, school environment or a society where gender discrimination is practised more so to the girl-child, the achievement gap is widened because the issue negatively impacts school performance. Gender discrimination increases the number of school drop-out, increases violence in school, and reduces the rate of transition and affect the overall performance of a school. Gender disparity has a negative effect on achievement gaps in senior high schools.

\subsection{School climate and achievement gaps}

The school climate system is complex and involves a multi-dimensional structure. Often, it has been defined as the unwritten atmosphere and personality of a particular school, involving its norms, expectations, culture, and its values. In addition, it has been defined as the precise character and quality of school life (Thapa, Cohen, Guffey, \& Higgins-D’Alessandro, 2013).

Most importantly, instead of the physical or administrative attributes of the school such as physical resources in school or teachers' salary, school climate is often based on the psychosocial school environment and the socioeconomic group interaction that impact the student learning and the overall school functioning. However, several sub-factors often exert a substantial impact on academic achievement; for example, academic optimism, academic emphasis, and powerful teacher-student relationships have been found to impact the achievement of the student strongly. In particular, the strong bond between a teacher and a student works as a protective factor for school conduct and academic achievement more so the teenagers who are transiting from primary to secondary school (Goldsmith, 2014). But how much of variance in student achievement is exacerbated by variations in school climate?

Some scholarly evidence post that school climate is the main predictor of students' behaviour and emotional outcomes. These emotional outcomes result into variations in student achievement especially for most at-risk students, overage pupils, students with low achievement scores, students from low social economic status etc. (Thapa et al., 2013). School climate directly affects the students' psychosocial adaptation and adjustment, which has a lifetime impact on the students on self-esteem and mental health outcome. The self-esteem of students from low SES and those most at risk of dropping out has been found to be low (Klein, Cornell, \& Konold, 2012). The school climate further influence the behaviour of students such as the level of aggression and bullying, alcohol and drug abuse, student delinquency among other things; finally, school climate influence has an impact on the academic achievement of students thereby having a direct effect on achievement gaps in senior high schools (Ethier et al., 2018; Machry et al., 2018).

\subsection{Methodology}

This study relied heavily on secondary data analysis to establish to what extent school environment exacerbates achievement gaps in various categories of schools, among different types of students. Senior high schools in Ghana are of different qualities based on their location (rural-urban divide), the quality of learners, and previous achievement as measured by mean standard scores of the schools (Asante, 2010). The variables of interest were proportional of children from low Social Economic Status (SES), proportional of vulnerable children like orphans and single parents, proportional of schools classified as lower cadre senior secondary schools, and proportional of schools with lower-quality teachers.

These variables were of interest as literature demonstrates that in conjunction with the school environment, they exacerbate achievement gaps among learners. A population of 250 students and 40 teachers was proportionately sampled from a population of 6635 senior high students and 750 teachers for qualitative studies to shed more light on to what extent the school environment is contributing to achievement gaps among students from low SES as compared to those from high SES, low-quality senior high schools as compared to those from high-quality senior high schools, students from rural schools as compared to those in urban areas. Both quantitative and qualitative data were collected from respondents and analysed, both descriptively and thematically. 


\subsection{Discussions and Findings}

From the analysis of the quantitative data, $58 \%$ of the senior schools were from rural, $42 \%$ of the schools were from urban schools. In trying to establish if the variance in students' achievement is associated with the quality of the senior high schools. A Chi-Square test of association was used between the two variables (quality of the senior school, code as $1=$ for high quality, and 2=low-quality schools) and student achievement. The Chi-Square results showed that there exists a significant relationship between the qualities of the schools (a measure of schools environment), and student achievement ; $\mathrm{X} 2(1, \mathrm{~N}=290)=8.8, \mathrm{p}=-.0029)$. This implied that school climate as measured by the quality of the school was negatively associated to student achievement such that high-quality schools which are normally characterised with state of the art classrooms, laboratories, halls and sports facilities as well as inherent technological muscle to aid in effective teaching and learning process. To add weight to these findings, during an interview, one student argued that rural schools are more disadvantaged than urban schools when it comes to availability of schools resources for the learning of science and technology subjects, and the student from the rural senior high schools reported as follows:

'I feel in our school we are disadvantaged as compared to those students from the big and established senior secondary schools. If you keenly observe, our labs are not as well build like theirs and yet we will be required to complete favorably during the final examinations. To us, this is a form of social marginalisation since it will be hard for some of us to proceed to university to pursue technical subjects from a school like this", Respondents No 16, During Interview of November 2019.

The second variable of interest to this study was to find out if the proportional of students from low SES which is a measure of classroom environment was closely associated to student achievement gaps between high quality senior high schools and lower-quality schools. The findings from the study were as follows.

Table 1: Proportional of Students Based on SES

\begin{tabular}{lll}
\hline & Proportion of Students & Based on their SES \\
\cline { 2 - 3 } & LOW & HIGH \\
\hline Rural senior schools & 62 & 41 \\
Urban Senior Schools & 38 & 59 \\
\hline
\end{tabular}

From the table 1, $62 \%$ of the students in rural senior high schools were from lower SES, while only $41 \%$ were from high SES; while $38 \%$ of the students in urban senior high schools were from low SES while $59 \%$ were from high SES. The Chi-square test of association between SES of students and their academic achievement shows a significant relationship between the two variables $(\mathrm{X} 2(1, \mathrm{~N}=290)=7.87, \mathrm{p}=-.0035)$. The results of the Chisquare association revealed that SES of students influenced their academic achievement with those from low SES performing slightly better in public rural senior high schools than in public urban senior high schools. To further establish if indeed SES had a negative influence in all categories of schools, few students were asked to report if coming from high SES or low SES has negatively influenced them in schools and one respondent reported that:

"I don't feel like where I come from has greatly influenced my performance, but I guess the level of resources in one's home may make him to have some extra advantages like extra books, payment of school fee on time and maybe affordability of private remedial tuition over the holiday. However, coming from high social status may be an advantage or disadvantage at the same time"' Respondent 15, interview schedule in November 2019. The third variable of interest to this study was establishing how having a large proportional of OVC (orphans and vulnerable children), which is an indicator of school social burden influences performance. Proportions of OVC were calculated for both rural and urban schools and the results are as shown in table 2.

Table 2: Proportion of OVC Children in both urban and Rural Schools

\begin{tabular}{ll}
\hline Nature of the senior school & Proportion of OVC Children \\
\hline Urban & 38 \\
Rural & 62 \\
Total & 100 \\
\hline
\end{tabular}

From table 2 above, a large proportion of OVC children are in rural senior secondary schools. Studies on schools environment indicate that those school with a significant population of children with special needs, learning difficulties, coming from lower economic status and those who are minorities especially in developed nations influence school environment and climate (Johnson, 2009). To establish the extent to which the proportion of OVC students in a class influences learning achievements, a Chi-square test of association was carried between the proportion of OVC children and student achievement. The Chi-square results indicated that achievement scores were negatively associated with the proportional of OVC children in the class $\left(\mathrm{X}^{2}(1, \mathrm{~N}=290)=9.62, \mathrm{p}=-.0012\right)$. This implies that the proportion of OVC children is negatively associated with student achievement scores. These findings concur with those of Perry and McConney (2010), who established that the achievement level of minority students was lower than that of non-minority students in the US.

\subsection{Findings and Conclusions.}

This study having exhaustively attempted to establish whether or not, school environment exacerbates achievement 
gaps among boys and girls in senior high schools in Ghana. This study has actually demonstrated that school environment can be measured at student level based on the proportion of poor students in the schools, the proportion of students from low SES, and the proportion of students with learning difficulties. This study established that when schools have a significant proportion of students who are minority, with learning difficulties, who are poor, who are at risk of dropping out, with high levels of truancy, with low entry behaviors, and or maybe coming from lower social economic status, this negatively affects schools environment which ultimately exacerbates achievement gaps among students. This implies that schools environment especially classroom environment can be negatively influenced by having a high proportion of students that have been mentioned above. The study recommends that the government of Ghana, should reduce achievement gaps between boys and girls, children from low SES; schools should reduce the burden of cost of education in the households by meeting the cost of tuition through capitation grants, abolish unapproved fees, extra classes fees and also offer affirmative action scholarships to maintain girls in schools and improve the participation and transition from one level of learning to the other.

\section{REFERENCES.}

Amponsah, M. O., Milledzi, E. Y., Ampofo, E. T., \& Gyambrah, M. (2018). Relationship between parental involvement and academic performance of senior high school students: The case of Ashanti Mampong Municipality of Ghana. American Journal of Educational Research, 6(1), 1-8.

Asante, K. O. (2010). Sex differences in mathematics performance among senior high students in Ghana. Gender and Behaviour, 8(2), 3279-3289.

Chapman, L., \& Ludlow, L. (2010). Can downsizing college class sizes augment student outcomes? An investigation of the effects of class size on student learning. jge: the journal of general education, 59(2), 105123.

Cheryan, S., Meltzoff, A. N., \& Kim, S. (2011). Classrooms matter: The design of virtual classrooms influences gender disparities in computer science classes. Computers \& Education, 57(2), 1825-1835.

Coleman, J. S., Campbell, E., Hobson, C., McPartland, J., Mood, A., Weinfeld, F., \& York, R. (1966). The coleman report. Equality of Educational Opportunity.

Ethier, K. A., Harper, C. R., \& Dittus, P. J. (2018). School environment is related to lower health and safety risks among sexual minority middle and high school students. Journal of Adolescent Health, 62(2), 143-148.

Everett Jones, S., Brener, N. D., \& McManus, T. (2003). Prevalence of school policies, programs, and facilities that promote a healthy physical school environment. American journal of public health, 93(9), 1570-1575.

Johnson, S. L. (2009). Improving the school environment to reduce school violence: A review of the literature. Journal of school health, 79(10), 451-465.

Klein, J., Cornell, D., \& Konold, T. (2012). Relationships between bullying, school climate, and student risk behaviors. School psychology quarterly, 27(3), 154.

Kumi-Yeboah, A. (2016). Educational resilience and academic achievement of immigrant students from Ghana in an urban school environment. Urban Education, 0042085916660347.

Lage, M. J., Platt, G. J., \& Treglia, M. (2000). Inverting the classroom: A gateway to creating an inclusive learning environment. The Journal of Economic Education, 31(1), 30-43.

Machry, R. V., Knorst, J. K., Tomazoni, F., \& Ardenghi, T. M. (2018). School environment and individual factors influence oral health related quality of life in Brazilian children. Brazilian oral research, 32.

Morton, K., Atkin, A., Corder, K., Suhrcke, M., \& Van Sluijs, E. (2016). The school environment and adolescent physical activity and sedentary behaviour: a mixed-studies systematic review. Obesity reviews, 17(2), 142158.

Perry, L. B., \& McConney, A. (2010). Does the SES of the school matter? An examination of socio-economic status and student achievement using PISA 2003. Teachers College Record, 112(4), 1137-1162.

Rasamiravaka, T., Rasoanandrasana, S., Zafindraibe, N. J. J., Alson, A. O. R., \& Rasamindrakotroka, A. (2013). Evaluation of methicillin-resistant Staphylococcus aureus nasal carriage in Malagasy patients. The Journal of Infection in Developing Countries, 7(04), 318-322.

So, H.-J., \& Brush, T. A. (2008). Student perceptions of collaborative learning, social presence and satisfaction in a blended learning environment: Relationships and critical factors. Computers \& Education, 51(1), 318-336.

Stiggins, R. (2015). Student-Centered Classroom Assessment. New York: Merrill US Congress, Office of Technology Assessment (1992). Testing America's Schools: Asking the Right Questions: OTA-SET-519 (Washington, DC: US Government Printing Office).

Thapa, A., Cohen, J., Guffey, S., \& Higgins-D’Alessandro, A. (2013). A review of school climate research. Review of Educational research, 83(3), 357-385. 